\title{
Determination of Material Density by Means of Computerized Tomography
}

\author{
Teodor Tóth ${ }^{1 *}$, Darina Glittová ${ }^{1}$, Tatiana Kelemenová ${ }^{1}$, Miroslav Dovica ${ }^{1}$ \\ 1 Department of Biomedical Engineering and Measurement, Faculty of Mechanical Engineering, Technical University of Kosice, Letna 9, 04200 \\ Kosice, Slovakia
}

\begin{abstract}
When evaluating dimensions, the crucial thing is the closest possible determination of a surface. Industrial computerized tomography works with relative material densities, therefore, unlike in medical fields, there is no need to assign particular density to individual shades of grey. In some cases, however, determination of material density or a variation of its density in a selected area is required. To establish the percentage of variation in density of a material, any surface determination is sufficient, as a ratio of two relative values is calculated therefrom.
\end{abstract}

Keywords: computed tomography, density, isosurface

\section{Introduction}

Treatment of morphological disorders of mandibular structure is intended to improve appearance and function, achieve proper occlusion, correct proportions, facial length and mandibular rami, as well as good shape of the chin [1, 2]. The facial region is a particularly difficult one to treat, since many delicate anatomical structures are found here. Less extensive disorders can be treated orthopedically, however the majority of disorders require surgical treatment.

Several factors influence determination of density by means of computerized tomography:

1. Material - the denser the material, the less precise determination of its density. With denser materials, the number of artifacts rises (beam hardening, scattering, ...).

2. Form - the more complex the form of the scanned object, the more the radiation scatters on its surface, thus the scattering possibility increases. The denser the object, the more pronounced the phenomenon.

3. Cumulative material thickness - the greater the cumulated thickness and density, the greater the material "non-homogeneity" due to non-homogeneity and X-ray radiation absorption. This effect is present in simple forms, too (a block, a cylinder...). Surfaces of metallic materials are subject to emergent beam hardening.

\section{Methodology of the Experiment}

Samples with known density were selected for the experiment. To avoid as many effects on measurement as possible, plastic samples were chosen. Tab. 1 presents particular types of material and their densities as per the respective material lists.

Individual samples used are of rectangular and cylindrical form of different sizes. The plastic objects were put into a space-efficient arrangement, with the plastic objects separated from one another by polystyrene.

The effect of scanned parameters and the effect of the use of a copper filter on 
Tab. 1: Material types and their densities.

\begin{tabular}{|l|l|}
\hline Material & Density $\left[\mathrm{kg} \cdot \mathrm{m}^{-3}\right]$ \\
\hline Polypropylene (PP) & 910 \\
\hline Polyamide (PA) & 1140 \\
\hline Polyvinyl chloride (PVC) & 1420 \\
\hline Polytetrafluorethylene (PTFE) & 2160 \\
\hline
\end{tabular}

scanning results was observed in course of scanning.

Four scanning steps were observed. All samples were scanned simultaneously in course of the first two scanning procedures, while scanning parameters were modified depending on a filter used. The sample arrangement is shown in Fig. 1. below.

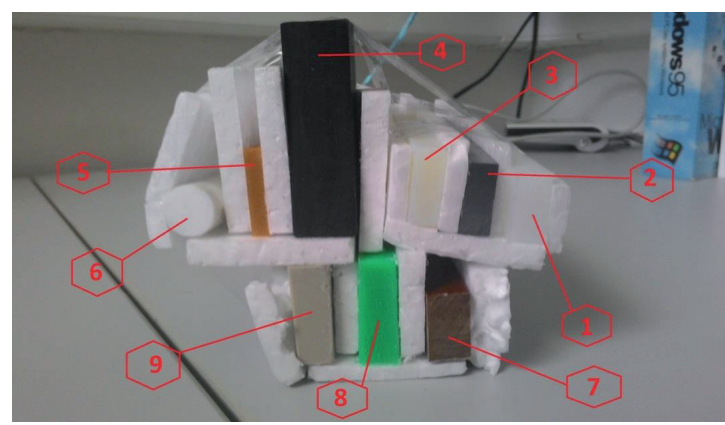

Fig. 1: Scanning sample arrangement.

1 - Polyethylene, 2 - Polyvinylchloride, 3 - Polyamide, 4 - Rubber, 5 - Polyurethane, 6 - Polytetrafluorethylene, 7 Textolite, 8 - Polyethylene, 9 - Polypropylene

Reconstructed samples were analyzed in an analyzing software VGStudio MAX v.2.2 (Fig. 2) from Volume Graphics (Germany). This software helped analyze $\mathrm{CT}$ values and the measured objects surfaces. An exact edge was determined by the ISO$50 \%$ method.

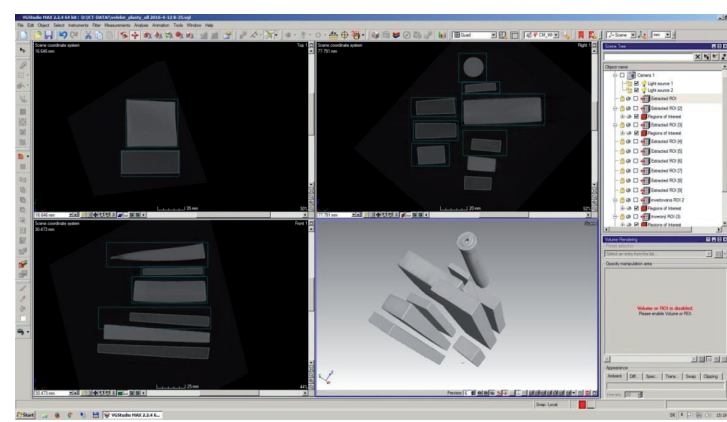

Fig. 2: Sample imaging and their reconstruction in VGStudioMAX.
To obtain relevant information from the given segments, the set thus generated had to be further separated into individual samples measured. The reason for segmentation is correct surface determination. Had the segmentation been skipped, the surface of a portion of materials would not have been determined correctly. An automatic material detection function was applied to material separated into individual portions. Because material homogeneity was assumed, as was the relative low density of the evaluated materials, manual selection of material was not necessary. Fig. 3 shows a histogram and an isosurface value (yellow frame) of a selected sample. In the upper part of the figure, surface and material values are highlighted.

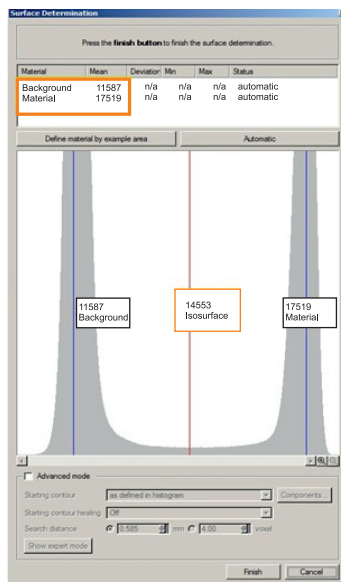

Fig. 3: Histogram and isosurface, air and material value presentation.

As precise as possible material surface determination is necessary to obtain the volume of an evaluated object, which can be further used for calculating the material density. The sample's volume value is highlighted in Fig. 4.

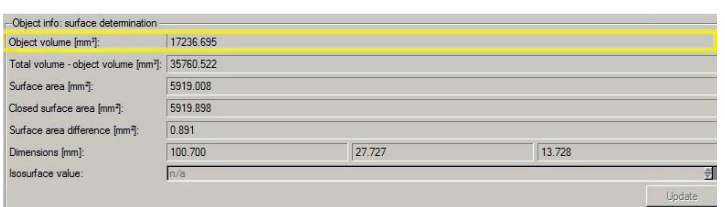

Fig. 4: Selected material sample volume.

To calculate their density, individual samples need to be weighed. The weighing was carried out by the use of laboratory scale Nagata FATH 065 with the weighing range of $300 \mathrm{~g}$ and $\mathrm{a} \pm 0,1 \mathrm{~g}$ deviation. 


\section{Material Density Evaluation}

\section{Sample scanning with a copper filter}

A $0.25 \mathrm{~mm}$-thick copper filter was used in scanning to remove soft radiation and contingent beam hardening. Filter deployment is not conventional with plastics, but in some directions, the material features great cumulative thickness with a potential to translate into non-homogeneities.

Scanning results concerning all samples, with the use of the filter, are presented in Tab. 2, with particular materials listed as per their catalog density.

\section{Sample scanning in the absence of a copper filter}

Filterless scanning was performed with a lesser current, as no filter loss needed to be compensated for.Tab. 3 presented results of measurements without the filter. Particular materials are listed as per their catalog density.

\section{Result summary}

This subchapter contains an analysis and an overall summary of the obtained results. Out of the latter, the isosurface value, the sample's volume obtained from the analysis, and the calculated density value merit further processing. The value of grey in the background and that of the material is unimportant due to dependence of the former on scanning, and the value of a sample's weight is constant for each material type.

Thanks to data from scanning all material types with the use of the filter as well as without its use, a summarizing Tab. 4 could have been produced.

The summarizing table (Tab. 5) makes it possible to determine differences between scanning with a filter and without one, where the difference between the parameters compared is expressed in an absolute value.

Tab. 2: Values obtained in filter measurements.

\begin{tabular}{|c|c|c|c|c|c|c|}
\hline \multirow[b]{2}{*}{ Material } & \multicolumn{3}{|l|}{ Value of grey } & \multicolumn{3}{|c|}{ Sample properties } \\
\hline & Background & Material & ISO surface & $\begin{array}{l}\text { Volume } \\
{\left[10^{-6} \mathrm{~m}^{3}\right]}\end{array}$ & $\begin{array}{l}\text { Weight } \\
{\left[10^{-3} \mathrm{~kg}\right]}\end{array}$ & $\begin{array}{l}\text { Density } \\
{\left[10^{-3} \mathrm{kgm}^{3}\right]}\end{array}$ \\
\hline Polypropylene & 11587 & 16924 & 14553 & 21.925 & 20.10 & 0.9167 \\
\hline Polyamide & 11677 & 18474 & 15076 & 12.159 & 13.84 & 1.1382 \\
\hline Polyvinylchloride & 11745 & 25378 & 18561 & 19.760 & 27.08 & 1.3703 \\
\hline Polytetrafluorethylene & 11640 & 24518 & 18709 & 13.696 & 29.52 & 2.1552 \\
\hline
\end{tabular}

Tab. 3: Values obtained in filterless measurements.

\begin{tabular}{|c|c|c|c|c|c|c|}
\hline \multirow[b]{2}{*}{ Material } & \multicolumn{3}{|l|}{ Value of grey } & \multicolumn{3}{|c|}{ Sample properties } \\
\hline & Background & Material & ISO surface & $\begin{array}{l}\text { Volume } \\
{\left[10^{-6} \mathrm{~m}^{3}\right]}\end{array}$ & $\begin{array}{l}\text { Weight } \\
{\left[10^{-3} \mathrm{~kg}\right]}\end{array}$ & $\begin{array}{l}\text { Density } \\
{\left[10^{-3} \mathrm{kgm}^{3}\right]}\end{array}$ \\
\hline Polypropylene & 8942 & 13762 & 11352 & 22.029 & 20.10 & 0.9124 \\
\hline Polyamide & 8992 & 15109 & 12050 & 12.056 & 13.84 & 1.1479 \\
\hline Polyvinylchloride & 9144 & 16174 & 12815 & 6.109 & 7.61 & 1.2455 \\
\hline Polytetrafluorethylene & 8902 & 21548 & 15225 & 13.343 & 29.52 & 2.2122 \\
\hline
\end{tabular}

Tab. 4: Summarizing table including all samples

\begin{tabular}{|c|c|c|c|c|c|c|}
\hline \multirow[b]{2}{*}{ Material } & \multicolumn{3}{|c|}{ Filter scanning } & \multicolumn{3}{|c|}{ Filterless scanning } \\
\hline & Background & Material & ISO surface & $\begin{array}{l}\text { Volume } \\
{\left[10^{-6} \mathrm{~m}^{3}\right]}\end{array}$ & $\begin{array}{l}\text { Weight } \\
{\left[10^{-3} \mathrm{~kg}\right]}\end{array}$ & $\begin{array}{l}\text { Density } \\
{\left[10^{-3} \mathrm{kgm}^{3}\right]}\end{array}$ \\
\hline Polypropylene & 14553 & 21.925 & 0.9167 & 11352 & 22.029 & 0.9124 \\
\hline Polyamide & 15076 & 12.159 & 1.1382 & 12050 & 12.056 & 1.1479 \\
\hline Polyvinylchloride & 15500 & 6.250 & 1.2174 & 12815 & 6.109 & 1.2455 \\
\hline Polytetrafluorethylene & 18709 & 13.696 & 2.1552 & 15225 & 13.343 & 2.2122 \\
\hline
\end{tabular}


Tab. 5: Difference in scanning with a filter and without one

\begin{tabular}{|c|c|c|c|c|c|c|}
\hline \multirow[b]{2}{*}{ Material } & \multicolumn{3}{|l|}{ Difference } & \multicolumn{3}{|c|}{ Difference in percentage value } \\
\hline & Background & Material & ISO surface & $\begin{array}{l}\text { Volume } \\
{\left[10^{-6} \mathrm{~m}^{3}\right]}\end{array}$ & $\begin{array}{l}\text { Weight } \\
{\left[10^{-3} \mathrm{~kg}\right]}\end{array}$ & $\begin{array}{l}\text { Density } \\
{\left[10^{-3} \mathrm{kgm}^{3}\right]}\end{array}$ \\
\hline Polypropylene & 3201 & 0.104 & 0.0043 & 21.9955 & 0.4743 & 0.4691 \\
\hline Polyamide & 3026 & 0.103 & 0.0097 & 17.3226 & 0.8471 & 0.8522 \\
\hline Polyvinylchloride & 2685 & 0.141 & 0.0281 & 17.2613 & 2.2560 & 2.3082 \\
\hline Polytetrafluorethylene & 3484 & 0.353 & 0.057 & 18.6221 & 2.5774 & 2.6448 \\
\hline
\end{tabular}

\section{Conclusion}

The analysis of the obtained data leads to a conclusion that notwithstanding a relatively great percentage variation in the isosurface value (1522\%), the percentage difference in density deviates from the value listed in catalog by less than 3\%, with the deviation being greater in materials displaying greater density.

Real density of individual samples subject to experiment has not been determined by any other, more precise methodology, therefore the percentage difference from a sample's real density cannot be determined.

Considering the fact that we do not know real densities of the materials in question (it is our assumption they are similar to the values listed in the respective catalogs) and in the light of the obtained results, the computerized tomography is a suitable method for obtaining densities of plastic materials.

\section{Acknowlegment}

The work was supported by research grant "Metrological processing of biomedical data obtained by $3 D$ scanners for educational purpose" (KEGA 063TUKE-4/2016) and "Researche of .contact and contactless strategies for coordinate measurement of freeform objects" (VEGA 1/0182/15).

\section{References}

[1] Velebír, J.: Metodika definovania hustoty vzoriek pomocou metrotomografie, Diplomová práca, TU SjF Košice, 2016

[2] Kruth, J.P., Bartscher, M., Carmignato, S., Schmitt, R., De Chiffre, L., Weckenmann, A.: Computed tomography for dimensional metrology, CIRP Annals - Manufacturing Technology, Volume 60, Issue 2, 2011

[3] Tóth, T., Végh, A., Dovica, M., Živčák, J.: Influences of Surface Determination for Measurements Obtained by Industrial Computed Tomography Applied Mechanics and Materials : WaPOL 2014 : Conference on Research, Production and
Use of Steel Ropes, Conveyors and Hoisting Machines, Volume 683 (2014), 2014, Pages 142-146.

[4] du Plessis A., Meincken, M., Seifert, T:: Quantitave determination of density and mass of polymeric materials using microfocus computed tomography, Journal of non destructing evaluation, 2013

[5] Mull, R.t.: Mass estimated by computed tomography; physical density from CT numbers, Am J. Roentgenol 143(5), 1984

\section{Biographical notes}

Doc. Ing. Teodor Tóth, PhD., received M.S. degree in mechanical engineering from Technical University of Košice, Slovakia in 2001 and PhD. degree in Biomedical Engineering from Technical University of Košice, Slovakia in 2009. Today Mr. Tóth is an associate professor in Measurement at Department of the Biomedical Engineering and Measurement at the Faculty of Mechanical engineering at the Technical University of Košice, Slovakia. His research interests include computed tomography and measurement in metrology and biomedical engineering. He is co-author of 2 monographies, 4 books and more than 80 journal and conference papers.

Ing. Darina Glittová, She is currently PhD. Student at the Department of Biomedical Engineering and Measurement at the Technical University of Košice, Slovakia. Her research interests include dimensional metrology, coordinate measurement and industrial computed tomography.

prof. Ing. Miroslav Dovica, PhD., received his M.S. degree in Mechanical Engineering from Technical University of Kosice, Slovakia in 1981 and Ph.D. in 2009. He is currently Professor of Metrology at the Department of Biomedical Engineering and Measurement at the Technical University of Košice, Slovakia. His research interests include dimensional metrology, coordinate measurement of free-form surfaces using contact and non-contact measurement system. 